\title{
Inventario Florístico preliminar del bosque de galería de la Microcuenca "Las Chichiguas", Jinotega, Nicaragua
}

\author{
Dania Paguaga ${ }^{1}$, María E. Juárez ${ }^{2^{*}}$
}

1. Herbario HULE, Departamento de Biología, Facultad de Ciencias y Tecnología, Universidad Nacional Autónoma de Nicaragua, León. 23115013 ext. 1136.

2. Departamento de Biología, Facultad de Ciencias y Tecnología, Universidad Nacional Autónoma de Nicaragua, León. 23115013 ext. 1190.

\section{RESUMEN}

Se presentan los resultados preliminares del Inventario Florístico del Bosque de Galería de la Microcuenca Las Chichiguas, Jinotega, Nicaragua. Este inventario permitirá conocer el estado actual de conservación especies de bosque primario en el bosque de galería. Se colectaron muestras en las cuatro diferentes zonas de usos de la microcuenca El Salto, en donde el uso del suelo es pasto y ganado; La Colmena, donde encontramos café con sombra y hortalizas; La Fuente, adonde se cultivan granos básicos y Mora Arriba que es el punto de aforo. Para cada zona se muestreó un área de amortiguamiento de $30 \mathrm{~m}$ a lo largo de la rivera del río.

Se han colectado hasta la fecha 129 individuos agrupados en 37 órdenes, 52 familias, 79 géneros y 100 especies. Del $100 \%$ de las especies colectadas en todas las zonas el $18 \%$ son indicadoras de Bosque Primario. De las zonas muestreadas La Fuente es la que tiene más especies (58), pero de éstas, sólo el $15 \%$ son de bosque primario, mientras que en La colmena donde se colectaron 25 especies, el $28 \%$ corresponden a especies de bosque primario.

\section{Palabra clave: Inventario Florístico.}

\section{INTRODUCCIÓN}

La problemática ambiental, social y económica que enfrenta Nicaragua está fundamentada en la explotación irracional de sus recursos naturales, repercutiendo en graves consecuencias para la salud y el futuro desempeño de la economía nicaragüense ${ }^{[1]}$.

El Ministerio de Recursos Naturales MARENA ${ }^{[2]}$, propone tres situaciones causantes de la insostenibilidad ambiental de cuencas hidrográficas del país:

-Explotación irracional de los recursos naturales.

-Problemas de contaminación y escasez de agua.

-Pérdida de productividad de los suelos (75\% anual) disminuye el potencial de crecimiento económico particularmente en la agricultura.

Una de las subcuencas más afectadas por esta problemática es la del Río Viejo. El Río Viejo nace en el municipio de San Rafael del Norte y desemboca en el Lago de Managua, siendo uno de los tributarios de la cuenca del Río San Juan que vierte sus aguas al océano Atlántico. Con una extensión de $19.47 \mathrm{~km}^{2}$ la microcuenca Las Chichiguas se encuentra en la parte alta de la subcuenca y fue catalogada como un área de sensibilidad ambiental y social por MARENA/PIMCHAS y Alianza Terrena en el año $2008^{[3]}$. La mayoría de los criterios aplicados resultaron ser de prioridad alta destacándose entre ellos las zonas buffer de quebradas y ríos con sobre uso de la tierra.

La elaboración de un inventario del bosque de galería de la microcuenca, donde se tome en cuenta el uso actual del suelo, permitirá la construcción de una estrategia para su restauración de los servicios ecológicos.

\section{DISEÑO METODOLÓGICO}

Se realiza un inventario del bosque de galería de la Microcuenca Las Chichiguas, Jinotega, tomando en cuenta los siguientes criterios:

-Se muestrea las cuatro diferentes zonas de usos: (EI Salto) pasto y ganado, (La Colmena) café con sombra y hortalizas, (La Fuente) granos básicos y (Mora Arriba) que es el punto de aforo de la microcuenca.

- Se monitorea un área buffer de $30 \mathrm{~m}$ sobre la rivera del río.

Los puntos de muestreos se han georreferenciado y todos los datos se han introducido en bases de datos relacionales. Luego se validó en campo la red de 
muestreo con un nuevo recorrido, para confirmar que las condiciones anteriormente descritas se cumplieron.

Para el inventario general se consideran: árboles, arbustos, lianas, bejucos y hierbas. En cada muestreo se han colectado de tres a cinco duplicados de cada especie con flores y frutos, de $30 \mathrm{~cm}$ de largo, los que se colocan en papel periódico debidamente rotulados con el primer nombre y apellido del colector.

Las muestras se conservan en alcohol al $70 \%$ y empacadas en bolsas para ser trasladadas al herbario de la UNAN-León donde se introducen al secador por un periodo de 3-5 días; posteriormente se identifican e introducen a la base de datos de plantas de Nicaragua del Herbario HULE, luego son archivadas en la colección del herbario, para que sirvan de referencia en muestreos futuros. Paralelo a la base de datos de HULE, se alimenta la base de datos para el monitoreo de bioindicadores.

Al momento de colectar las muestras se anota en el libro de campo los siguientes datos: Localidad de la colecta, coordenadas geográficas y la descripción de la planta, que incluye la forma de vida, presencia de látex, coloración de las flores y frutos, caracteres útiles para la identificación del material seco.

\section{RESULTADOS Y DISCUSIÓN}

Se han colectado hasta la fecha 129 individuos agrupados en 37 órdenes, 52 familias, 79 géneros y 100 especies. Las familias con mayor número de especies son: Solanaceae (12), Verbenaceae (6), Rubiaceae (5), Asteraceae (5), Euphorbiaceae, Fabaceae, Mimosaceae y Piperaceae (4), Moraceae y Myrsinaceae (3). Los géneros con más especies son: Solanum (9), Ardisia, Croton y Piper (4), Ficus y Hamelia (3), Erythrina, Lantana, Syngonium y Trichilia (2).

En cuanto al número total de especies de las cuatro zonas de usos del suelo muestreadas, La Fuente, donde se cultivan granos básicos, es la zona que presenta mayor cantidad de especies con un total de 58 y las zonas de Mora Arriba (zona de aforo de la microcuenca) y La Colmena (café de sombra y hortalizas) tienen 25 especies, seguido por El Salto que es la zona de pasto y ganadería con 21 especies.

En cuanto al estado de conservación actual del bosque de galería, del $100 \%$ de las especies colectadas en todas las zonas, el $18 \%$ son indicadoras de Bosque Primario. Es importante mencionar que La Fuente es la zona que presenta la mayor cantidad de especies (58) de las cuales, el $84.48 \%$ corresponde a especies de

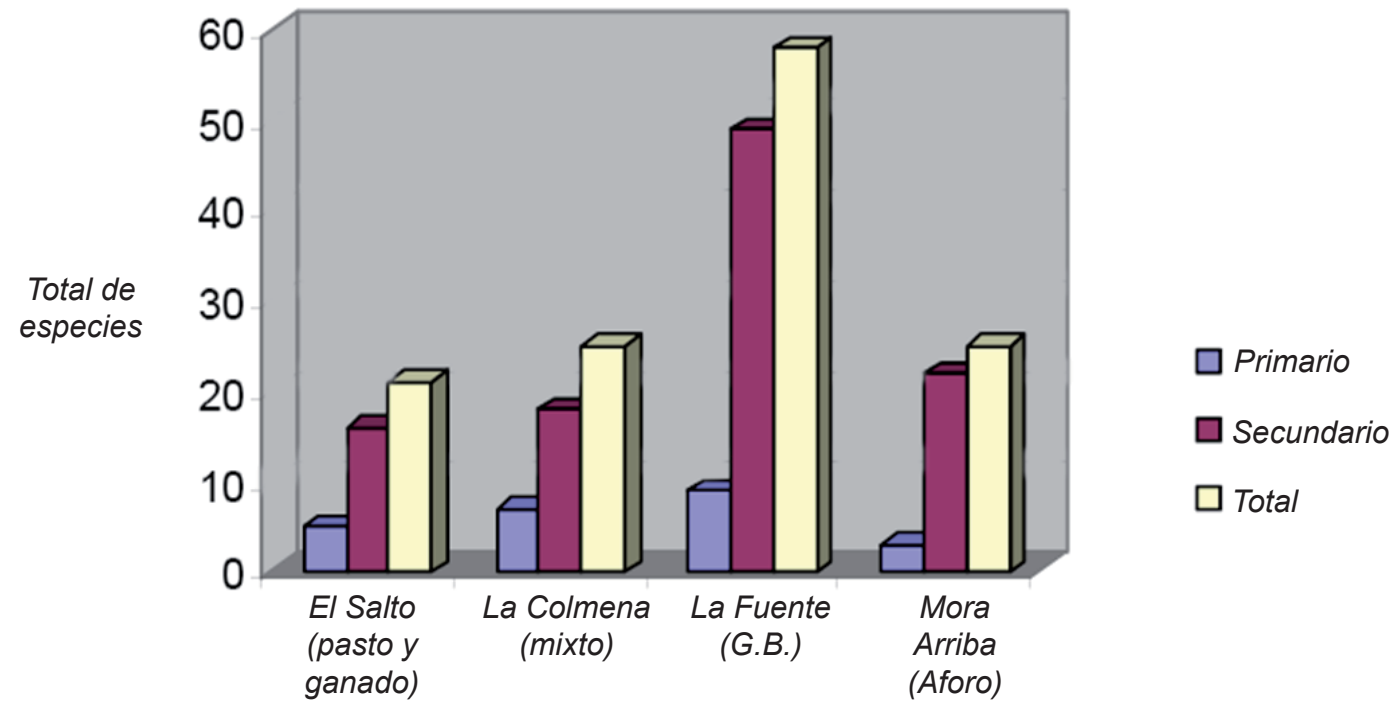

Figura 1. Cantidad de Especies por Uso del Suelo en la Microcuenca Las Chichiguas, Jinotega. 


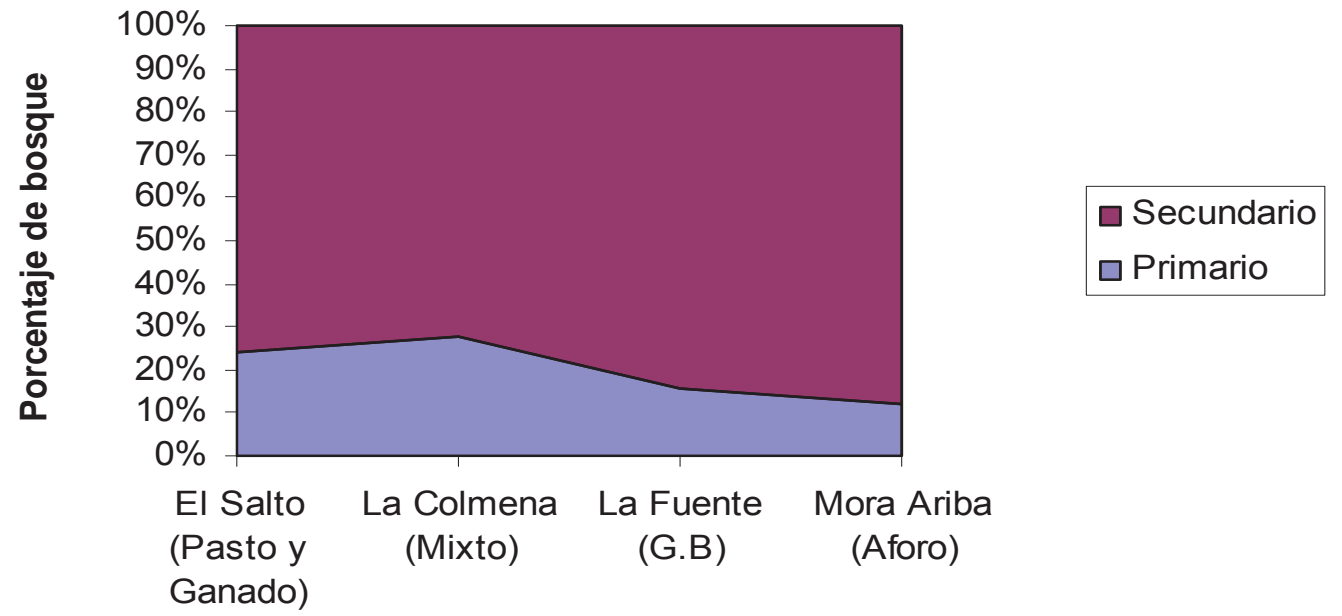

\section{Uso de suelo}

Figura 2. Porcentaje de Especies de Bosque Primario y Secundario por áreas muestreadas en cuanto al uso del Suelo en la microcuenca Las Chichiguas, Jinotega.

bosque secundario, típicas de áreas perturbadas. Cabe destacar, que aunque esta área presente la mayor cantidad de especies colectadas no significa que sea la más conservada. Es la zona de La Colmena la que presenta el porcentaje más alto de especies primarias. En las figuras 1 y 2 que se presentan a continuación se muestra con claridad este resultado.

De las 18 especies de Bosque Primario encontradas en las cuatro zonas, ocho son árboles, siete son arbustos y tres son epifitas, agrupadas en las siguientes familias: Meliaceae (2), Capparaceae, Styracaceae, Olacaceae, Moraceae, Fabaceae y Boraginaceae (1) para árboles; Myrsinaceae (3), Rubiaceae (2), Piperaceae y Mimosaceae (1) para los arbustos; Araceae (2) y Liliaceae (1) para epifitas.

A continuación, se presenta listado de especies de bosque primario presentes en los remanentes de bosque de galería de la microcuenca Las Chichiguas: Ardisia bracteosa DC., Ardisia compressa Kunth, Ardisia opegrapha Oerst. subsp. Opegrapha, Bomarea edulis (Tussac) Herb., Capparis discolor Donn.Sm., Cojoba sophorocarpa (Benth.) Britton \& Rose, Ehretia latifolia DC.,Erythrina steyemarkii Krukoff \& Barneby, Ficus crassiuscula Warb. ex Standl., Hamelia axillaris Sw. Hamelia longipes Standl., Piper bredemeyeri Jacq., Schoepfia schreberi J.F. Gmel., Styrax argenteus C.Presl., Syngonium angustatum Schult., Syngonium podophyllum Schott, Trichilia havanensis Jacq., Trichilia martiana C. DC.
En cuanto a importancia por distribución, las siguientes especies según la flora de Nicaragua se consideran poco comunes:

Erythrina steyermarkii Krukoff \& Barneby, es una especie común de bosques húmedos, se encuentra frecuentemente a lo largo de arroyos, generalmente en la zona atlántica; 0-800 m; la importancia de esta especie radica en que tiene una distribución muy limitada, pues se encuentra de Nicaragua a Costa Rica, donde es Nativa y se conocen colectas de Río San Juan, pero en la Cordillera Dariense de Nicaragua esta especie parece formar híbridos con Erythrina lanceolata, con la que puede confundirse.

Styrax argenteus C.Presl. es una especie ocasional de bosques montanos húmedos en la zona norcentral; 400-1300msnm y es nativa de México a Panamá. De las especies centroamericanas es la más común, pero actualmente es catalogada como una especie rara e indicadora de bosque primario.

Schoepfia schreberi J.F. Gmel es una especie común en bosques húmedos y deciduos en todas las zonas del país; Estados Unidos (sur de Florida) y este de México hasta el norte de Sudamérica, también en las Antillas. Schoepfia tiene 23 especies reconocidas, 19 en América tropical y 4 especies de Asia. S. vacciniiflora Planch. ex Hemsl. es conocida en México, Guatemala, El Salvador, Costa Rica y Panamá. Es, sin embargo, una especie que crece a grandes alturas y raramente se la encuentra por debajo de los $1500 \mathrm{~m}$, por lo tanto es probable que no se encuentre en Nicaragua. Lo novedoso, es que la encontramos a $1043 \mathrm{msnm}$. 
Ardisia opegrapha Oerst. subsp. Opegrapha, común, en bosques húmedos y muy húmedos, zonas atlántica y norcentral; va desde Nicaragua a Panamá. Existe una amplia variación en el tamaño relativo entre las inflorescencias y hojas, y en la persistencia de las brácteas en esta especie. Aunque Lundell describió varias especies, las formas inter-medias encontradas dentro de una población no permiten el reconocimiento de aquellas. El nombre Ardisia esquipulasana Lundell fue publicado como un nomen novon para Graphardisia nicaraguensis, pero no fue aceptado al momento de la publicación.

Capparis discolor Donn.Sm., especie hermosa y compleja, bastante variable, aún no conocida de Nicaragua; pluvioselvas a nebliselvas, desde México (Veracruz) hasta Colombia. Se parece a C. frondosa, pero tiene los pétalos, los estambres, los ginóforos y las semillas más grandes y las hojas suavemente atenuadas sobre el pecíolo; cuando en fruto es similar a $C$. heydeana, pero las semillas son más pequeñas, el fruto no es tan macizo y su corteza es más delgada, flexible y más suave.

Probablemente hay 2 taxones incluidos en este nombre y sólo estudios de campo detallados podrán resolver este problema taxonómico. Para Nicaragua, esta especie estaba reportada sólo para Río San Juan y el Atlántico norte, especialmente en Nueva Güinea, por tanto, es nuevo el lugar de colecta de esta especie.

Syngonium angustatum Schult., común en bosques siempreverdes y caducifolios, en las zonas pacífica y atlántica; 50-300 m; fl may-ago, fr jul-ene; desde México hasta el norte de Costa Rica. Esta especie puede confundirse con S. podophyllum, sin embargo esta última tiene 3-5 folíolos los cuales son más anchos e irregulares y los tallos son lisos y frecuentemente glaucos. Se colectó a 1109msnm.

\section{CONCLUSIONES}

Las cuatro zonas de uso de suelo muestreadas en la microcuenca Las Chichiguas presentan especies indicadoras de perturbación en el bosque de galería, siendo La Fuente la que presenta mayor cantidad de especies de bosque secundario.

El uso del suelo incide en la composición del bosque ya que el área donde se cultiva café bajo sombra y hortalizas el porcentaje de especies de bosque primario es mayor.

Capparis discolor Donn.Sm., para Nicaragua, esta especie estaba reportada sólo para Río San Juan y el
Atlántico norte, por ende, es nuevo el lugar de colecta de esta especie.

Schoepfia schreberi J.F. Gmel es una especie común en bosques húmedos y deciduos en todas las zonas del país. Sin embargo, estaba reportada para alturas mayores a 1500 msnm, y se colectó a 1043msnm.

\section{AGRADECIMIENTOS}

A CARE/MARENA/PIMCHAS que es la organización que provee los fondos económicos para esta investigación, al Señor Héctor Pastrán de la Alcaldía de la Concordia y el Sr. Cristiam Olivas egresado de la carrera de Biología quienes acompañan las giras de campo, al personal del Herbario de la UNAN-León, quienes ayudan en la identificación de las muestras y al profesor Ricardo Rueda, Ph.D por la revisión de este artículo. Este articulo forma parte de la tesis de Maria Encarnación Juárez, conducente al grado de doctorado del programa de doctorado en Ciencias Naturales para el desarrollo.

\section{REFERENCIAS BIBLIOGRÁFICAS}

1. Stevens, W. (2001). Flora de Nicaragua, Missouri Botanical Garden Press, Estados Unidos, Vol I, Vol II, III.

2. MARENA. (2006). Informe del Estado del Ambiente del país. Managua, Nicaragua. Tercer Informe Informe GEO 2003-2006.

3. CARE/MARENA/PIMCHAS y Alianza Terrena. (2008). Plan de Cuenca de la parte alta de la subcuenca del Río Viejo, Managua, Nicaragua. 1-20 y 35-45 Pág. 